\title{
Fertility in Austria: An Overview
}

\section{Tomáš Sobotka*}

This overview of Austrian fertility trends and patterns looks first at the basic trends in the total number of births by birth order and the main indicators of fertility, including estimates of parity distribution among selected birth cohorts of women. The subsequent sections review the trends in nonmarital childbearing, multiple births, fertility timing, and age-specific patterns of fertility. The final section features period and cohort indicators of parity progression. It looks in particular at the progression to first birth and at period progression rates to second and third birth among women past age 30 . This analysis is further complemented by the parity progression indicators based on the duration since the previous birth.

The period analysed here is not strictly defined and depends to some extent on data availability. Most of the figures and tables focus on the period and cohort fertility realised between 1960 and 2004 and, due to data limitations, a number of parity-specific indicators depict only the trends in the last two decades.

\section{Main Trends in Period and Cohort Fertility}

Figure 1:

Births by birth order and total deaths in 1960-2004

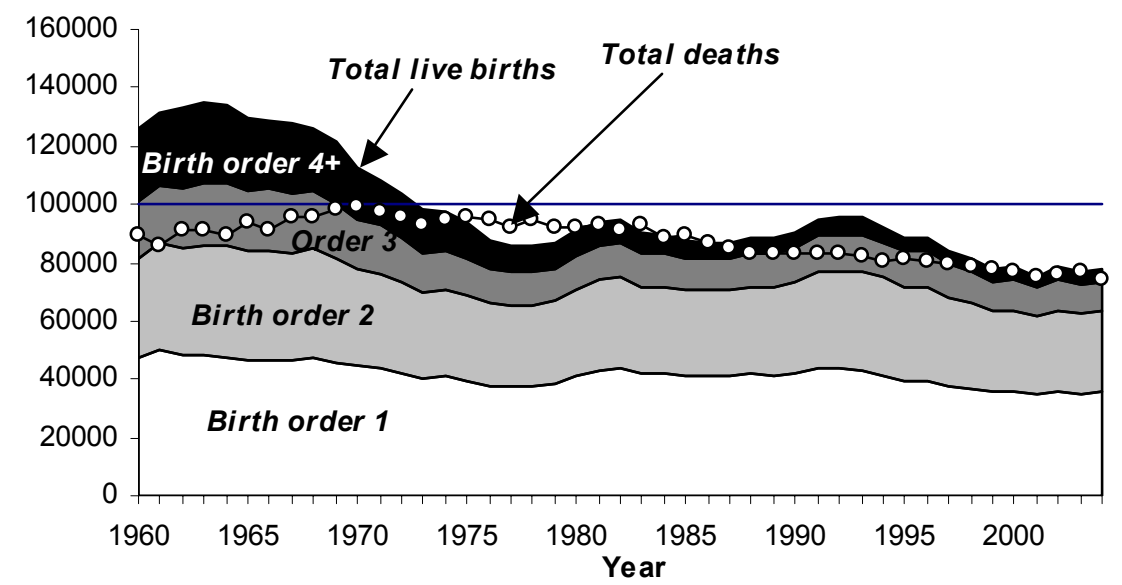

Sources: Author's estimates based on the 1981 Population Census data (Statistics Austria 1989) and computations based on the database of births in 1984-2004 provided by Statistics Austria.

\footnotetext{
* Vienna Institute of Demography, Prinz-Eugen-Strasse $8,2^{\text {nd }}$ floor, A-1040 Vienna, Austria. Email: tomas.sobotka@oeaw.ac.at
} 
- The total number of live births fell steadily between $1963(134,800)$, when the peak of the baby boom had been reached, and $1978(85,400)$. After that it fluctuated, reaching the record low value of 75,500 in 2001.

- The steep decline in the total number of live births after 1963 was primarily caused by a reduction in the number of third and subsequent births.

- The number of $4^{\text {th }}$ and further births dropped by $81 \%$ between 1962 $(27,600)$ and $1990(5,200)$ and reached an all-time low in $2001(4,200)$.

- The total number of deaths outnumbered the recorded live births in 19751980, 1983, 1985-86, and by a small margin, also in 1999 and 2003.

Table 1:

Main indicators of birth and fertility for 1960-2004 (selected years)

\begin{tabular}{rccccccccr}
\hline Year & $\begin{array}{c}\text { Total } \\
\text { live } \\
\text { births }\end{array}$ & $\begin{array}{c}\text { Natural } \\
\text { increase }\end{array}$ & $\begin{array}{c}\text { First } \\
\text { births } \\
(\%)\end{array}$ & $\begin{array}{c}\text { Third+ } \\
\text { births } \\
(\%)\end{array}$ & $\begin{array}{c}\text { Total } \\
\text { fertility } \\
\text { rate }\end{array}$ & $\begin{array}{c}\text { PAP- } \\
\text { rates }\end{array}$ & $\begin{array}{c}\text { Mean } \\
\text { age at } \\
\text { child- } \\
\text { birth }\end{array}$ & $\begin{array}{c}\text { Non- } \\
\text { marital } \\
\text { births } \\
(\%)\end{array}$ & $\begin{array}{r}\text { Multiple } \\
\text { deliveries } \\
\text { (per 1000) }\end{array}$ \\
\hline 1960 & 125,945 & 36,342 & 37.48 & 35.34 & 2.695 &.. & 27.59 & 13.28 & 10.82 \\
1963 & 134,809 & 43,230 & 35.63 & 36.35 & 2.819 &.. & 27.42 & 11.80 &.. \\
1970 & 112,301 & 13,482 & 39.56 & 30.68 & 2.291 &.. & 26.67 & 12.77 & 9.16 \\
1980 & 90,872 & $-1,570$ & 45.00 & 22.06 & 1.651 &.. & 26.26 & 17.78 & 8.87 \\
1990 & 90,454 & 7,502 & 46.20 & 18.94 & 1.458 & 1.691 & 27.21 & 23.55 & 10.53 \\
2000 & 78,268 & 1,488 & 45.45 & 18.55 & 1.364 & 1.497 & 28.20 & 31.30 & 13.17 \\
2001 & 75,458 & 691 & 46.03 & 18.54 & 1.329 & 1.494 & 28.38 & 33.06 & 15.37 \\
2002 & 78,399 & 2,268 & 45.65 & 19.08 & 1.394 & 1.577 & 28.55 & 33.80 & 15.01 \\
2003 & 76,944 & -265 & 45.80 & 19.13 & 1.378 & 1.568 & 28.75 & 35.27 & 16.23 \\
2004 & 78,968 & 4,676 & 46.11 & 18.84 & 1.416 & 1.610 & 28.83 & 35.92 & 15.60 \\
\hline
\end{tabular}

Sources: See Figure 1.

Notes: PAP rates (Period average parity) is an indicator of total fertility based on parity-specific incidence rates by the duration from the previous birth (for the definition, see article of Sobotka et al. in this volume).

- In 1963, the proportion of third and later births (36.4\%) outnumbered the proportion of first births $(35.6 \%)$. The proportion of first births increased to $45 \%$ by 1980 and remained stable thereafter, whereas the proportion of third and later births declined to $19 \%$ in 1990 .

- The total fertility rate had dropped by almost half between 1963 (2.82) and 1990 (1.46). Being less affected by ongoing fertility postponement, the period average parity (PAP rates; see note below Table 1) remained above the TFR level in the 1980s and 1990s, reaching values around 1.6.

- Mean age at childbearing increased from the lowest recorded value of 26.2 in the late 1970 s to 28.8 in 2004.

- The proportion of nonmarital births had declined during the baby boom period to $12 \%$ in 1963 . A steep rise followed, tripling it to $36 \%$ in 2004 . 
Figure 2:

Total fertility rate, period and cohort indicators; $1950-2004$

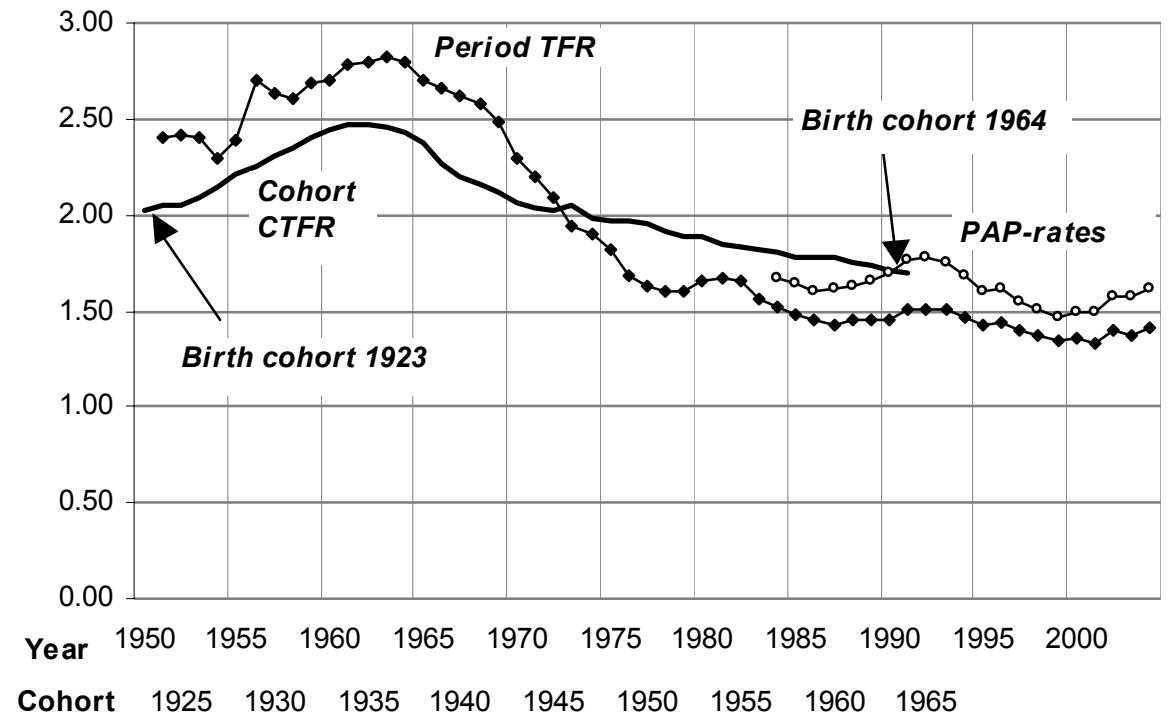

Sources: Council of Europe (2005) and author's computations based on the database of births in 1984-2004 provided by Statistics Austria.

Notes: See Table 1 for a definition of the Period average parity (PAP-rates).

- Although the completed cohort fertility rate (CTFR) exhibits less pronounced fluctuations than the period $T F R$, it also shows a considerable increase that is attributable to the baby boom of the late 1950s and the early 1960s: women born in 1934-35 reached the CTFR of 2.47 , which was by $22 \%$ higher than women born in 1923 (CTFR of 2.03).

- Women born after 1935 reached progressively smaller family sizes; the reduction in completed cohort fertility was rather steep among women born between 1937 (CTFR of 2.43) and 1943, who reached belowreplacement fertility level (2.06).

- The decline in completed fertility continued, if gradually, among women born after World War II. The cohort of 1960 has 1.77 children on average and the cohort of 1964 is likely to reach the completed fertility of 1.70 . 
Figure 3:

Cohort parity distribution among women born in 1910-1964

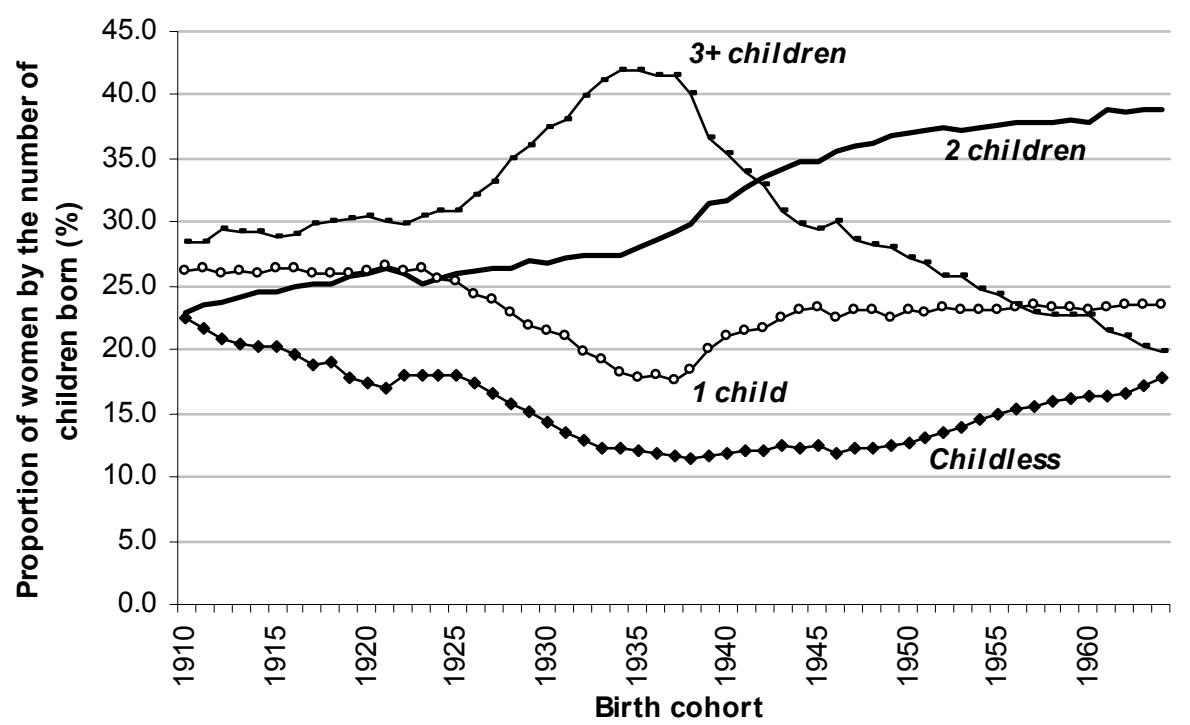

Sources: Population Census 2001 (Statistics Austria 2005). Population Census 1991 (Statistics Austria 1996) for birth cohorts 1910-1920.

Note: For women who have not reached the end of their reproductive period (cohorts 1955-1964), the final parity distribution is based on their cumulated cohort fertility on January 1, 2005 and estimated fertility realised after that date.

- The baby boom generations attained low levels of childlessness, which declined to about $12 \%$ among women born in 1933-49. Furthermore, they were characterised by a decline in the proportion of women having only one child to about $18 \%$ among the cohorts of 1934-38. In contrast, the proportion of women having three or more children had shot up from less than $30 \%$ among women born in $1910-16$ to more than $40 \%$ among those born in 1933-38.

- The growth of two-child families had been initiated before the baby boom era and continued uninterrupted thereafter. Two children constitute the most common family size among women born since 1942. The proportion of women with two children reached close to $40 \%$ among those born in the first half of the 1960s.

- Larger families have become less common: the proportion of women having three or more children declined by more than half, from $42 \%$ (birth cohorts 1934-35) to about 20\% (cohort 1964). In comparison, final childlessness increased gradually among women born in the 1950s and early 1960 s, reaching about $18 \%$ among those born in 1964 . The proportion of women with only one child has been remarkably stable at $22-24 \%$ among the cohorts born since the early 1940s. 
Table 2:

Final parity distribution among women born in 1910-1964 (selected birth cohorts, in \%)

\begin{tabular}{lccccc}
\hline Birth cohort & Childless & 1 child & 2 children & 3+ children & $\begin{array}{c}\text { Total cohort } \\
\text { TFR }\end{array}$ \\
\hline 1910 & 22.4 & 26.2 & 22.9 & 28.4 & 1.87 \\
1920 & 17.4 & 26.1 & 25.9 & 30.5 & 1.99 \\
1930 & 14.4 & 21.4 & 26.7 & 37.5 & 2.31 \\
1935 & 12.1 & 17.8 & 28.1 & 42.0 & 2.47 \\
1940 & 11.9 & 21.0 & 31.8 & 35.3 & 2.21 \\
1950 & 12.6 & 23.1 & 37.0 & 27.3 & 1.96 \\
1960 & 16.3 & 23.1 & 37.9 & 22.7 & 1.77 \\
1964 & 17.8 & 23.6 & 38.9 & 19.8 & 1.70 \\
\hline
\end{tabular}

Sources and note: See Figure 3 .

\section{Nonmarital Childbearing}

Figure 4: Proportion of nonmarital births in Austria (total and first births) and selected provinces, 1950-2004

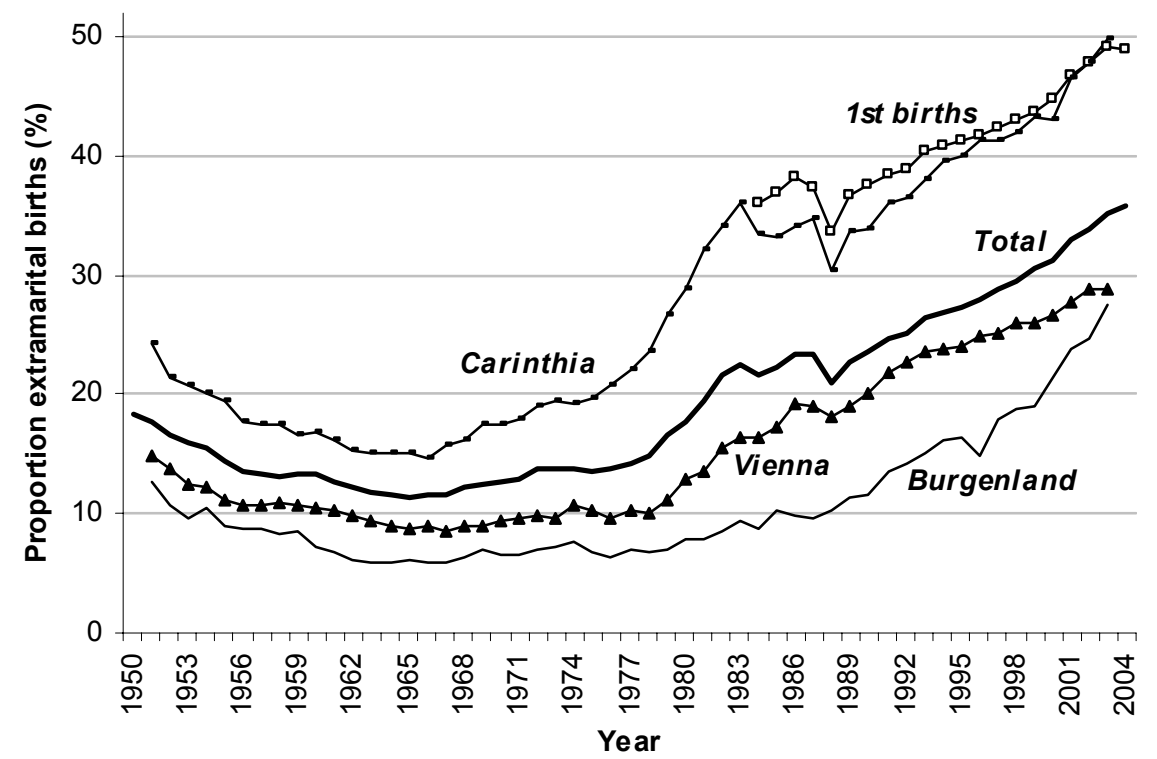

Sources: Statistics Austria 2005a and 1988; United Nations 1960 and author's computations based on the database of births in 1984-2004 provided by Statistics Austria.

- After reaching a $20^{\text {th }}$ Century low of $11.5 \%$ in 1965 , the proportion of nonmarital births increased steeply between 1978 and 1983 and then again since 1989 . Nonmarital childbearing has become very common in 
the case of first births: currently almost one half of first births occur outside wedlock (49\% in 2003 and 2004).

- $\quad$ Pronounced regional differences persist: in Carinthia, one half (49.8\%) of births were realised outside marriage in 2003, whereas the capital city Vienna $(29 \%)$ or the province of Burgenland (28\%) were well below the Austrian average of $35 \%$. However, the relative spatial differences in the proportion of nonmarital births have declined in the last 20 years.

Figure 5:

Distribution of first births by the marital status of mother at birth and at conception, 1984-2004

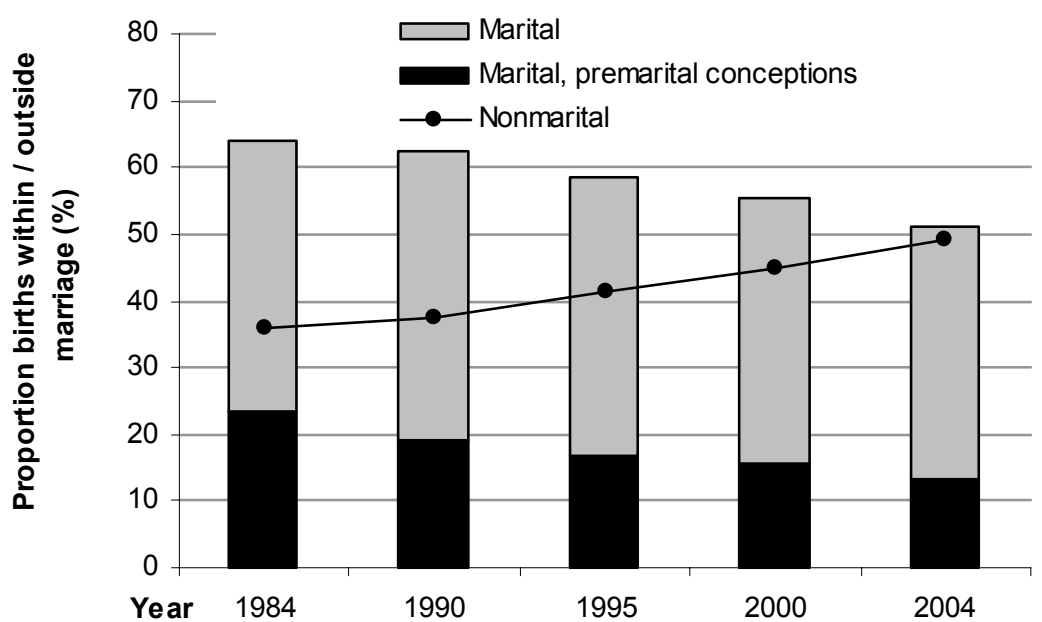

Sources: Author's computations based on the birth database for 1984-2004 provided by Statistics Austria.

Note: Premarital conceptions are estimated from the number of first births within 8 months following the marriage (data refer to the 'true' (biological) birth order).

- The overall decline in the proportion of first births realised within wedlock was particularly due to lower frequency of "shotgun weddings" and the resulting reduction in the proportion of marital first births that were conceived before marriage. In 2004 , only $13 \%$ of the total of first (biological) births occurred within eight months following marriage, down from $23 \%$ in 1984.

- The proportion of other marital first births declined only gradually, from $43 \%$ in 1990 to $38 \%$ in 2004 . 


\section{Multiple Births}

Figure 6:

Multiple deliveries (per thousand total deliveries), 1940-2004

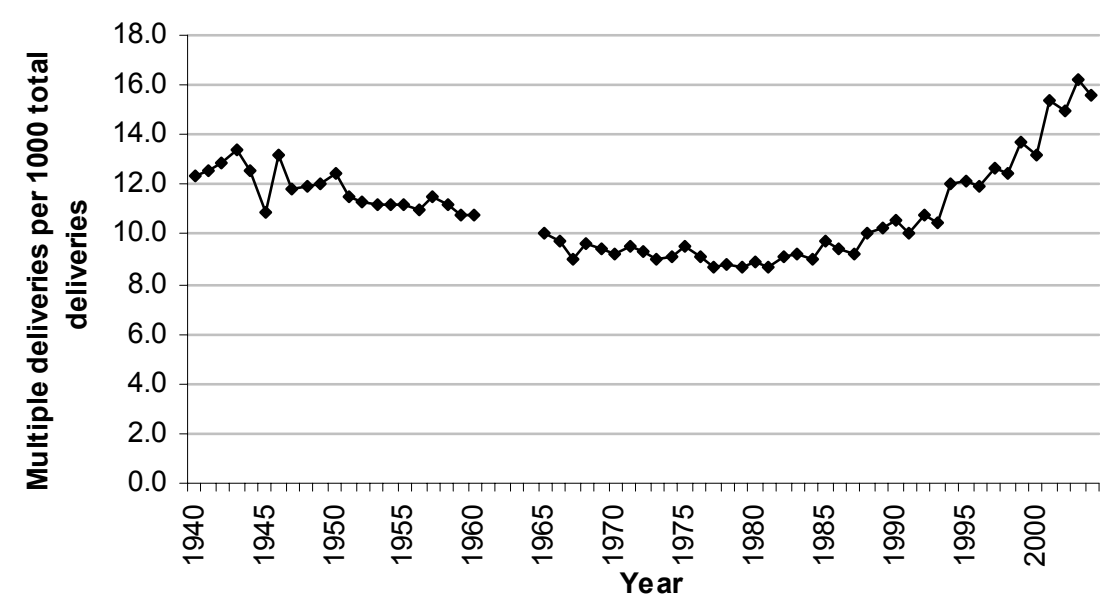

Sources: Author's computations based on Statistics Austria 2005a and the birth database for 2004 provided by Statistics Austria

- The gradual decline in the incidence of multiple deliveries after World War II to less than 9 per thousand deliveries in 1977-81 was followed by a steady increase in the period of 1988-2003, reaching above 15 multiple deliveries per thousand deliveries since 2001. This translates to more than $3 \%$ of the total live births being born from multiple deliveries.

- The recent increase was primarily due to the influence of two major factors associated with higher rates of multiple deliveries: a rising maternal age and the increasing use of infertility treatment.

- The incidence of triplets has increased much faster than the incidence of twins. Between 1977-81 and 2000-2004, the average annual incidence of twin deliveries increased by a factor of 1.7 (from 8.7 to 14.7 per thousand deliveries), whereas the incidence of triplets rose by a factor of 5.3 (from 0.08 to 0.41 per thousand deliveries). 


\section{Indicators of Fertility Timing}

\section{Figure 7:}

Mean age at childbearing (total and first births) and median age at first birth, 19502004

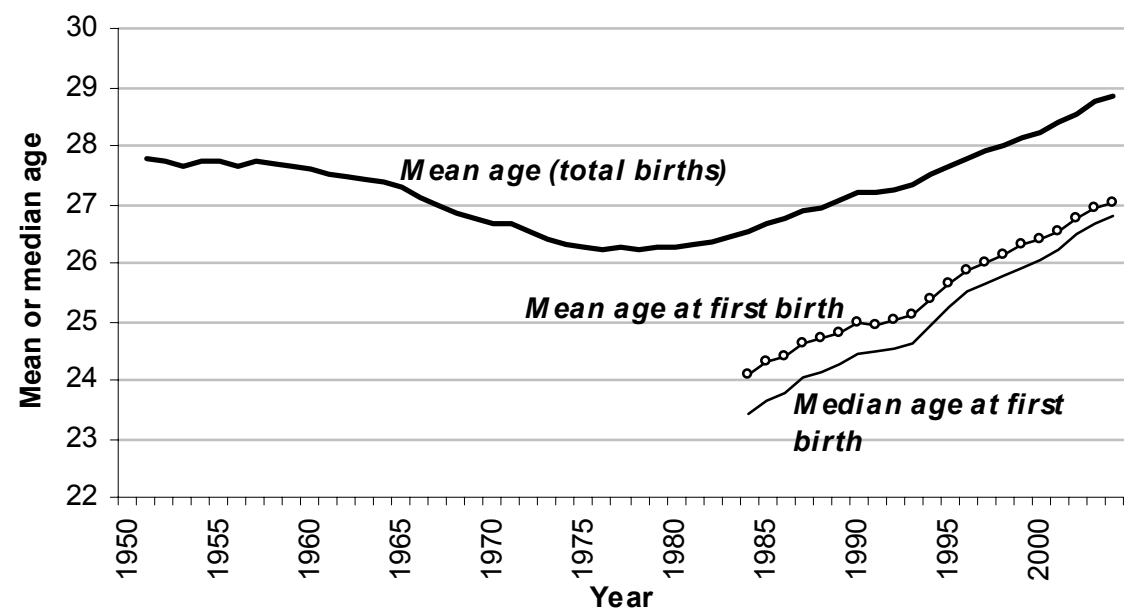

Sources: Council of Europe (2005) and author's computations based on the birth database for 1984-2004 provided by Statistics Austria.

- Mean age at childbearing has been increasing continually after 1980 . The increase in childbearing age was more pronounced among first-time mothers: women postponed the birth of their first child on average by about 3.5 years between the late 1970s and 2004, when the mean age at first birth reached 27 years. The median age at first birth was increasing even more rapidly, converging close to the level of the mean age.

- The graph of age-specific fertility rates (see Figure 8 below) illustrates the general shift of childbearing towards higher reproductive ages very well. The 1970 fertility schedule depicts an early childbearing pattern, with the peak at ages 21-22 (161 and 162 births per thousand women, respectively). In 2004, fertility rates among women aged 21 were down by $74 \%$ in comparison with 1970 , while the peak in fertility rates shifted to ages $28-30$ and became less pronounced (100-101 per thousand women). 
Figure 8:

Age-specific fertility rates per thousand women aged 15-42; 1960-2004

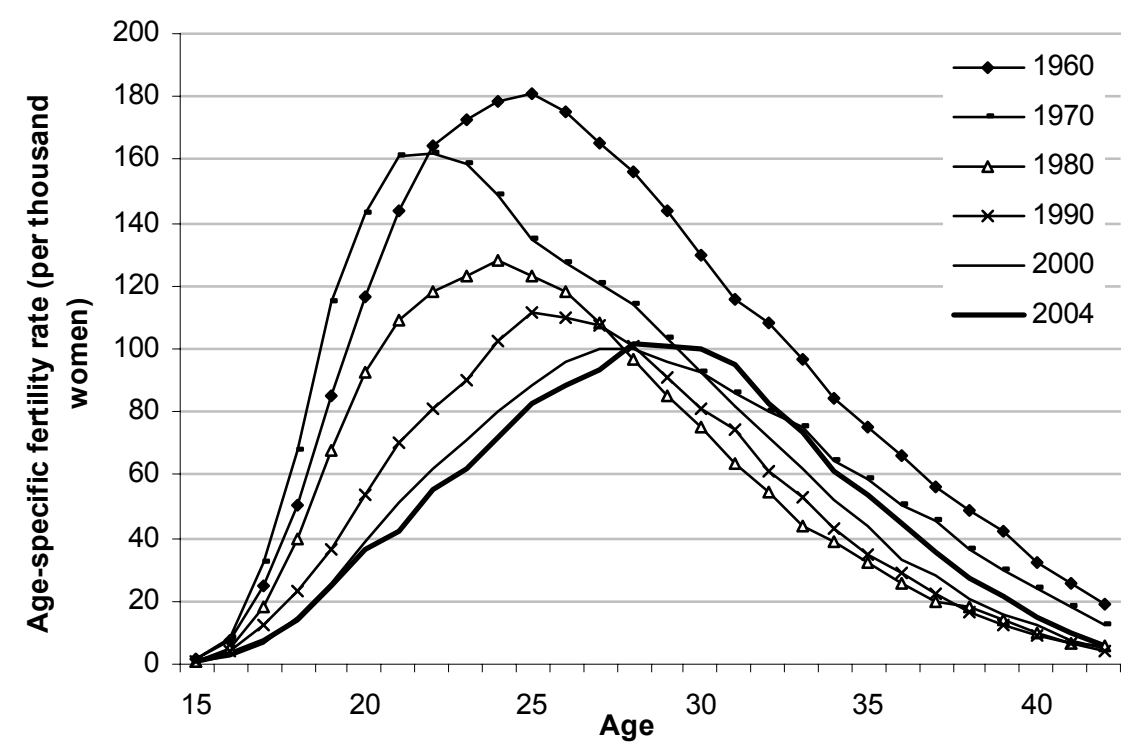

Sources: Author's computations based on EUROSTAT (2005) and the birth database for 1984-2004 provided by Statistics Austria.

Note: Data refer to age reached during the year (cohort age).

Table 3:

Sum of age-specific fertility rates (per thousand women) and the proportion of fertility rates realised below age 20 and at ages 30+; selected years 1960-2004

\begin{tabular}{lcccccccc}
\hline Year & $\begin{array}{c}\text { Below } \\
20\end{array}$ & $20-24$ & $25-29$ & $30-34$ & $35-39$ & $40+$ & $\begin{array}{c}\text { Share } \\
<20 \\
(\%)\end{array}$ & $\begin{array}{c}\text { Share } \\
30+ \\
(\%)\end{array}$ \\
\hline 1960 & 224.7 & 813.4 & 798.2 & 507.1 & 265.8 & 86.7 & 8.3 & 31.9 \\
1963 & 279.3 & 826.9 & 829.2 & 531.6 & 269.6 & 85.4 & 9.9 & 31.4 \\
1970 & 293.2 & 774.5 & 580.6 & 380.2 & 203.2 & 61.3 & 12.8 & 28.1 \\
1980 & 173.9 & 590.0 & 510.6 & 253.7 & 97.8 & 26.3 & 10.5 & 22.9 \\
1990 & 101.7 & 431.9 & 512.8 & 288.6 & 101.9 & 20.1 & 7.0 & 28.2 \\
2000 & 67.7 & 327.7 & 483.5 & 336.5 & 125.7 & 23.5 & 5.0 & 35.6 \\
2001 & 67.4 & 303.0 & 462.4 & 341.1 & 129.0 & 26.3 & 5.1 & 37.3 \\
2002 & 68.2 & 305.4 & 480.8 & 367.3 & 144.0 & 28.1 & 4.9 & 38.7 \\
2003 & 65.4 & 286.9 & 471.2 & 371.9 & 152.4 & 29.9 & 4.7 & 40.2 \\
2004 & 68.3 & 289.9 & 476.4 & 390.4 & 162.9 & 29.9 & 4.8 & 41.1 \\
\hline Index 2004/1963 & 0.24 & 0.35 & 0.57 & 0.73 & 0.60 & 0.35 & & \\
Index 2004/2000 & 1.01 & 0.88 & 0.99 & 1.16 & 1.30 & 1.27 & & \\
\hline
\end{tabular}

Sources: Council of Europe (2005) and author's computations based on the birth database for 2004 provided by Statistics Austria.

Notes: Data refer to age in completed years. 
- $\quad$ Since the early 1960 s, fertility declined most rapidly among women at the beginning and at the end of their reproductive span: below age 25 and after age 40. Between 1963 and 2004, fertility rates among women below age 20 dropped by three quarters.

- More recently, fertility was increasing among women past age 30 as a consequence of delayed childbearing. The onset of this increase can be traced back to 1979 for the age group 30-34, whereas for women aged 40 and older, there has been an increase in fertility rates only since 1989 .

- After 2000 , fertility rates have been increasing most rapidly among women past age 35 . Only women aged 20-24 have experienced a further significant reduction in their fertility rates.

Figure 9:

Proportion of fertility rates realised below age 25 and at age $30+$

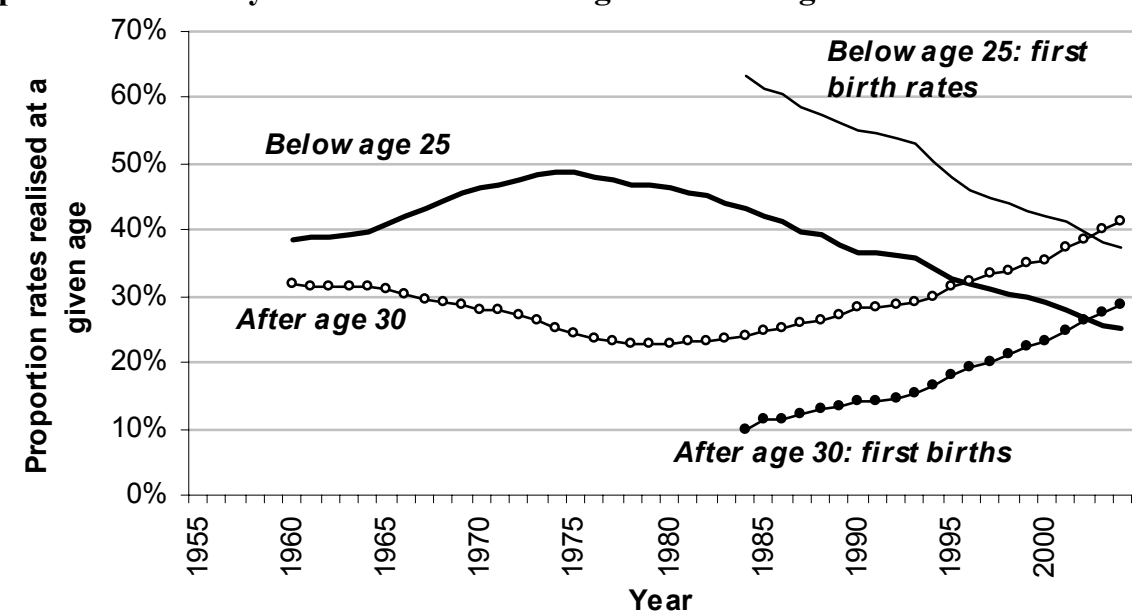

Sources: Author's computations based on Council of Europe (2005) and the birth database for 1984-2004 provided by Statistics Austria.

Notes: Data refer to age in completed years; graphs for first births are estimated from the data on fertility rates by age reached during the year (cohort age).

- The proportion of fertility rates realised by women aged below 25 had increased until the mid-1970s, when it reached almost one half (49\%). After that, it has been going down, reaching $25 \%$ in 2004 . In contrast, the proportion of fertility realised among women aged 30+ has continually risen from less than $23 \%$ in $1978-80$ to $41 \%$ in 2004 , exceeding the share of fertility rates below age 25 since 1996 .

- The shift toward later childbearing has been even more marked in the case of first births: In 1984 almost two thirds (63\%) of first birth rates were realised among women below age 25 and only one tenth among women aged 30 and older. Thereafter the share of this latter group has increased steadily to $29 \%$ in 2004 . 
Table 4:

Indicators of first birth timing: Deciles (10\% and $90 \%)$ and quartiles $(25 \%$ and $\mathbf{7 5 \%}$ ) of the distribution of first birth incidence rates, interquartile range (IQR), and interdecile range $(I D R)$ in 1984-2004

\begin{tabular}{lccccccc}
\hline & $10 \%$ & $25 \%$ & $\begin{array}{c}\text { Median age } \\
(50 \%)\end{array}$ & $75 \%$ & $90 \%$ & IQR & IDR \\
\hline 1984 & 19.05 & 20.82 & 23.42 & 26.66 & 30.01 & 5.84 & 10.96 \\
1990 & 19.40 & 21.48 & 24.43 & 27.72 & 31.30 & 6.24 & 11.90 \\
1995 & 19.70 & 21.99 & 25.26 & 28.67 & 32.14 & 6.68 & 12.44 \\
2000 & 20.09 & 22.56 & 26.05 & 29.67 & 33.13 & 7.11 & 13.04 \\
2001 & 20.03 & 22.65 & 26.21 & 29.94 & 33.44 & 7.29 & 13.41 \\
2002 & 20.12 & 22.80 & 26.47 & 30.21 & 33.70 & 7.41 & 13.59 \\
2003 & 20.21 & 22.97 & 26.68 & 30.42 & 33.97 & 7.44 & 13.76 \\
2004 & 20.19 & 23.04 & 26.81 & 30.60 & 34.16 & 7.57 & 13.97 \\
\hline $2004-1984$ & 1.14 & 2.22 & 3.39 & 3.94 & 4.15 & & \\
\hline
\end{tabular}

Sources: Author's computations based on the birth database provided by Statistics Austria.

Notes:

$I Q R$ - interquartile range; computed as a difference between the ages at which $25 \%$ and $75 \%$ of first birth rates were realised.

IDR: interdecile range; computed as a difference between the ages at which $10 \%$ and $90 \%$ of first birth rates were realised.

- $\quad$ Table 4 indicates an increasing differentiation in first birth timing: most women have delayed their entry into motherhood, yet a significant proportion of women still become mothers at a very young age.

- $\quad$ Whereas the median age has increased by 3.4 years to 26.8 between 1984 and 2004, one tenth of first birth rates in 2004 were realised among women below age 20.2 and one quarter among women below age 23. In contrast, the age after which the last tenth of first births occur has risen steadily to 34.2 in 2004 , i.e., by 4.2 years over the previous two decades.

- Consequently, the indicators of heterogeneity in first birth timing have increased markedly; the interdecile range has risen from 11.0 years to 14.0 years between 1984 and 2004. 


\section{Parity-specific Indicators of Fertility. Period and Cohort Perspective}

Figure 10:

Proportion of women who have given birth to at least one child at selected ages; birth cohorts 1915-1984

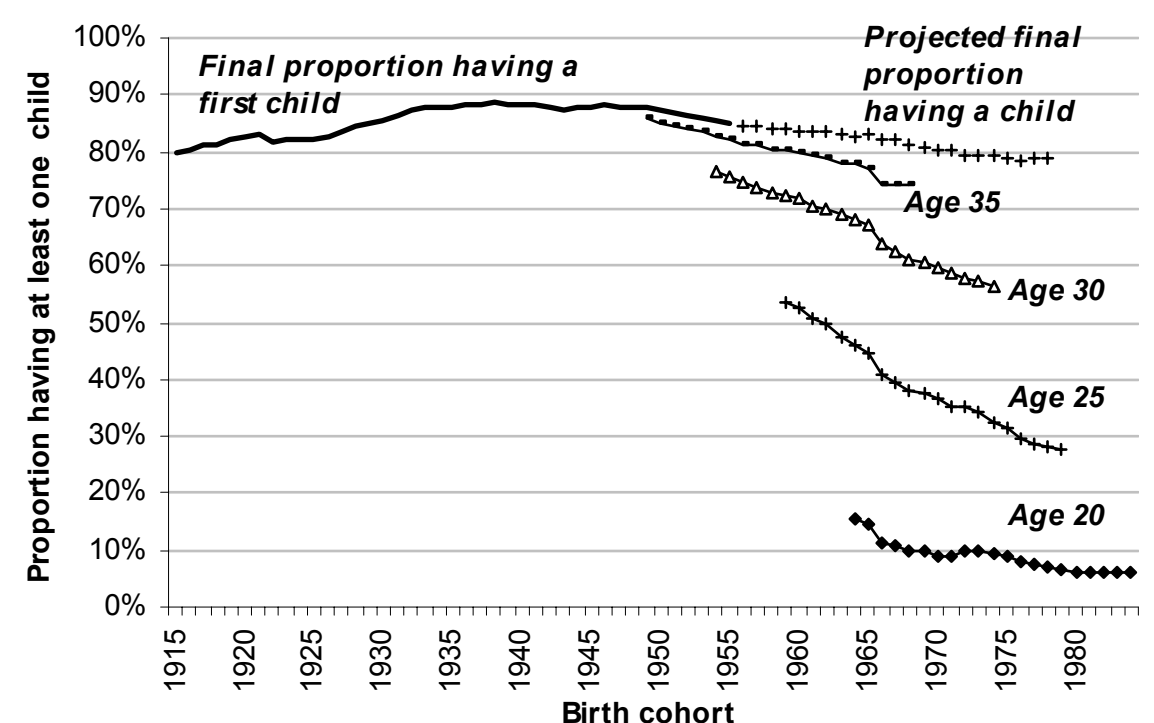

Sources: Author's computations based on Population Census 2001 (Statistics Austria 2005), Population Census 1991 (Statistics Austria 1996) and the database of births in 1984-2004 provided by Statistics Austria.

Notes: Data break in 2001 (break between the series based on the 1991 Population Census and the series based on the 2001 Population Census). The projected final proportion having a child among women born in 1960-1978 is based on the lower-bound projection of childlessness in Sobotka (2005).

- Due to the general increase in childlessness combined with the postponement of family formation, the number of women having at least one child has declined sharply at younger ages (until their early 30s), and gradually at ages 35 and higher.

- $\quad$ The proportion of women having a child at age 20 declined from $16 \%$ among women born in 1964 to 6\% among those born in 1984. By age 25, more than half $(53 \%)$ of the women born in 1959 had a child; this proportion dropped to $28 \%$ among women born in 1979 . Only one quarter of women born in 1954 were childless at age 30; subsequently, childlessness at that age increased steadily, reaching $40 \%$ among women born in 1970 and 44\% among those born in 1974 (see also Table 5).

- Final childlessness reached the lowest level, around 12\% among women born in 1932-48. Then it increased to $15 \%$ among women born in 1955; the lower-bound projection scenario (Sobotka 2005) envisions a further gradual increase to $19 \%$ among women born in 1970 and to $20 \%$ among those born in the mid-1970s. 
Table 5:

Proportion of women remaining childless at selected ages; birth cohorts 1950-1979

\begin{tabular}{lcccccc}
\hline $\begin{array}{l}\text { Birth } \\
\text { cohort }\end{array}$ & Age 20 & Age 25 & Age 30 & Age 35 & Age 40 & $\begin{array}{c}\text { Final } \\
\text { childlessness }\end{array}$ \\
\hline 1950 &.. &.. &.. & 14.8 & 13.3 & 12.6 \\
1955 &.. &.. & 24.4 & 17.9 & 15.9 & 15.0 \\
1960 &.. & 47.4 & 28.1 & 20.3 & 17.2 & $(16.3)$ \\
1965 & 85.6 & 55.5 & 33.0 & 22.3 & & $(17.1)$ \\
1970 & 90.9 & 63.4 & 39.3 & & & $(19.1)$ \\
1975 & 91.2 & 67.8 & & & & $(20.2)$ \\
1979 & 93.2 & 71.7 & & & & \\
\hline
\end{tabular}

Sources: see Figure 10.

Notes: Presented data are estimates of the proportion of women childless at the time of reaching age 20, 25, 30, etc., computed as the mean value of childlessness on January 1 and December 31 in the year when a given birth cohort reached their $20^{\text {th }}, 25^{\text {th }}$, etc. birthday.

Data break in 2001 (break between the series based on the 1991 Population Census and the series based on the 2001 Population Census).

Data in italics refer to the lower-bound projection of childlessness (see Sobotka (2005)).

.. means no data available; empty space indicates data for cohorts which have not yet reached the ages indicated.

\section{Figure 11:}

Period probability of having a first child during selected age intervals among women childless at the beginning of these age intervals (1984-2004)

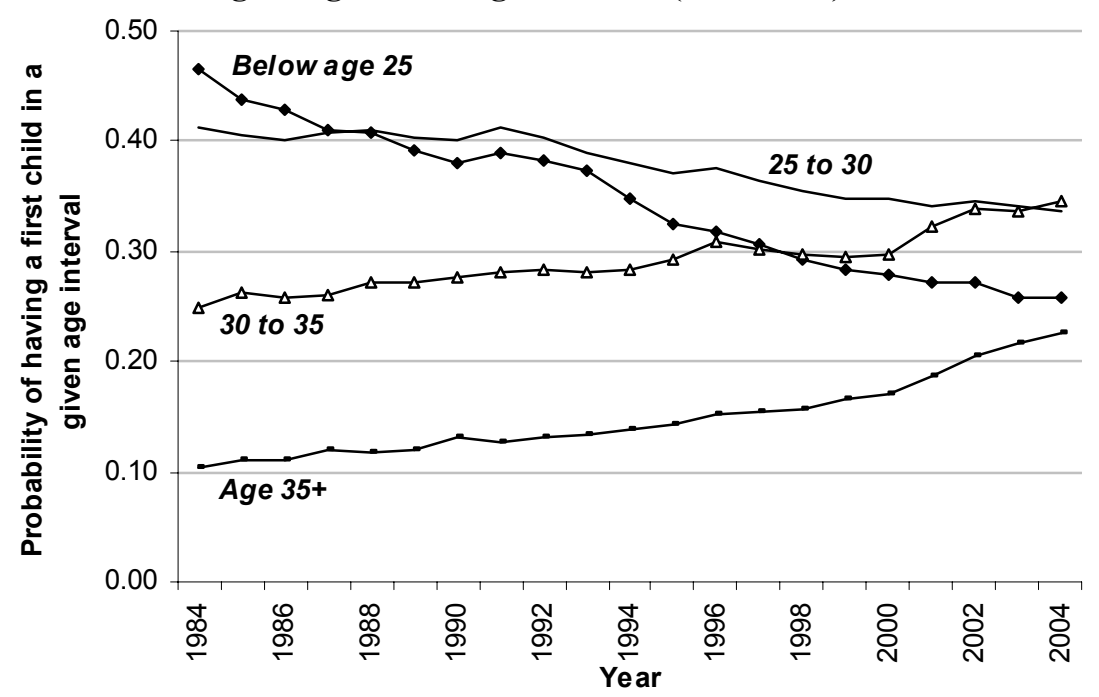

Sources: Author's computations based on the database of births in 1984-2004 provided by Statistics Austria and the Population Census 2001 (Statistics Austria 2005) and 1991 (Statistics Austria 1996) data on age-parity distribution of the female population.

Note: Indicators are based on age-parity fertility tables.

- $\quad$ The period age-specific probabilities of having a child among women still childless at a given age reflect the ongoing shift towards childbearing at higher ages. There has been a sharp decline in the probability of having a 
child below age 25 , from 0.46 in 1984 to 0.26 in 2004 . The decline has been less pronounced among women aged 25-30.

- Conversely, there has been a gradual increase in the probability that a woman still childless when reaching age 30 will give birth to a child before age 35 , from 0.25 to 0.35 in 1984-2004, and a stronger increase in the probability of ever having a child among women still childless at age 35 , from 0.10 to 0.23 .

Figure 12a:

Period lifetime probability of ever having a(nother) child after age 30 by parity at reaching age 30 (1984-2004)

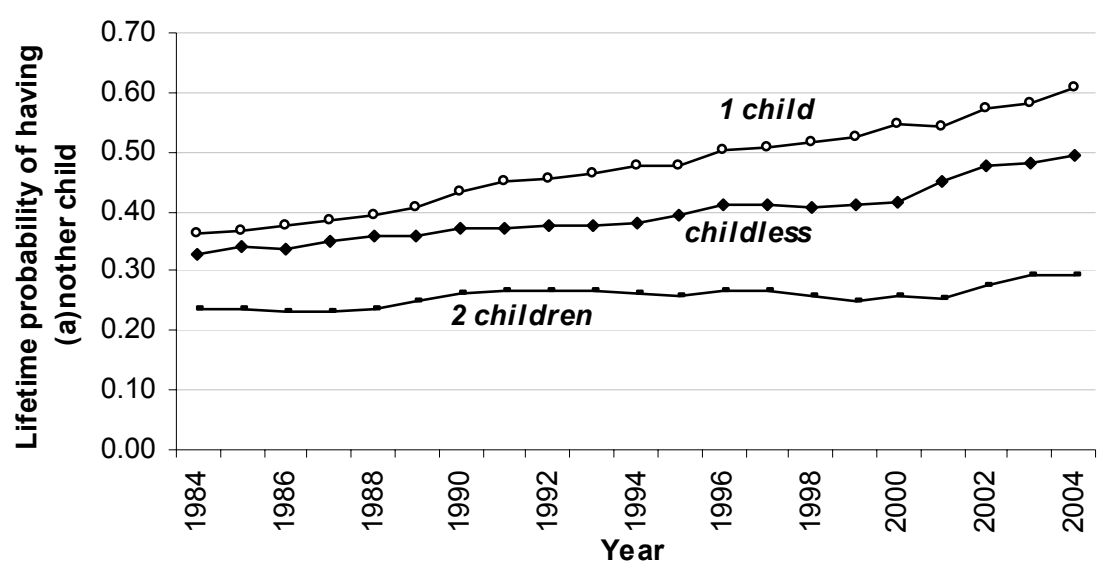

Figure 12b:

Period lifetime probability of ever having a(nother) child after age 35 by parity at reaching age 35 (1984-2004)

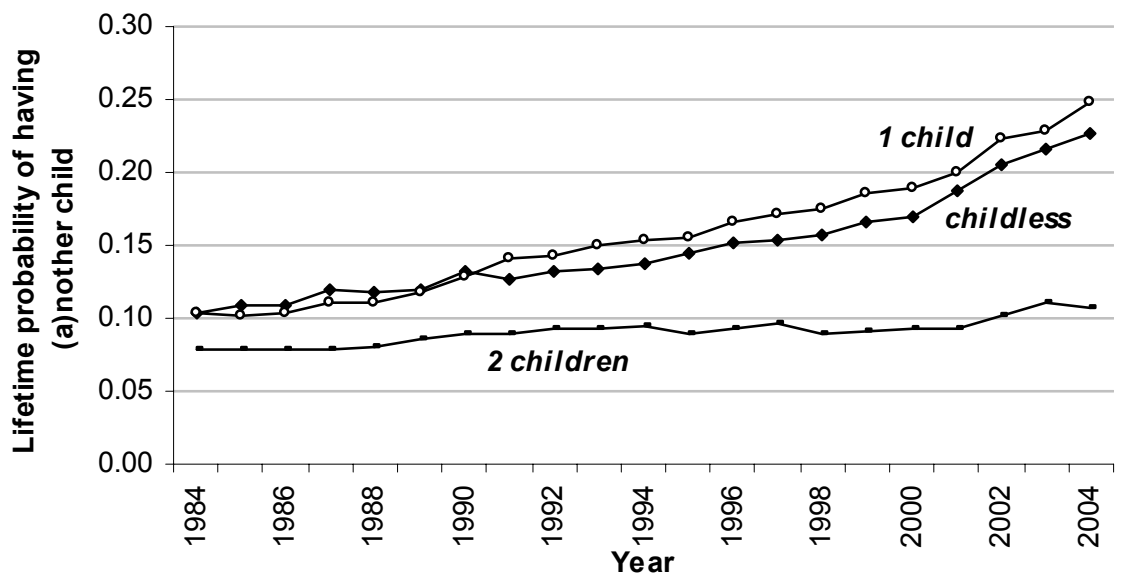

Sources: Author's computations based the on database of births in 1984-2004 provided by Statistics Austria and the Population Census 2001 (Statistics Austria 2005) and Population Census 1991 (Statistics Austria 1996) data on the age-parity distribution of the female population.

Note: Indicators are based on age-parity fertility tables. 
- The increase in the period probability of ever having a(nother) child after age 30 differed by parity. The propensity to have another child rose most intensively for women with one child, from 0.36 in 1984 to 0.61 in 2004. For childless women, the period probability of ever having a child reached almost one half $(0.49)$ in 2004 , up from 0.33 in 1984 . The same trend was much more gradual for women with two children (increase from 0.24 in 1984 to 0.29 in 2004).

- The relative changes have been even more pronounced for women aged 35: the period probability of ever having a child has increased more than twofold between 1984 and 2004 for childless women (from 0.10 to 0.23 ) and for women with one child (from 0.10 to 0.25 ).

- These trends indicate a strong orientation towards a two-child family model.

Figure 13:

Cumulative proportion of women having an additional child by the year at giving the previous birth and by duration

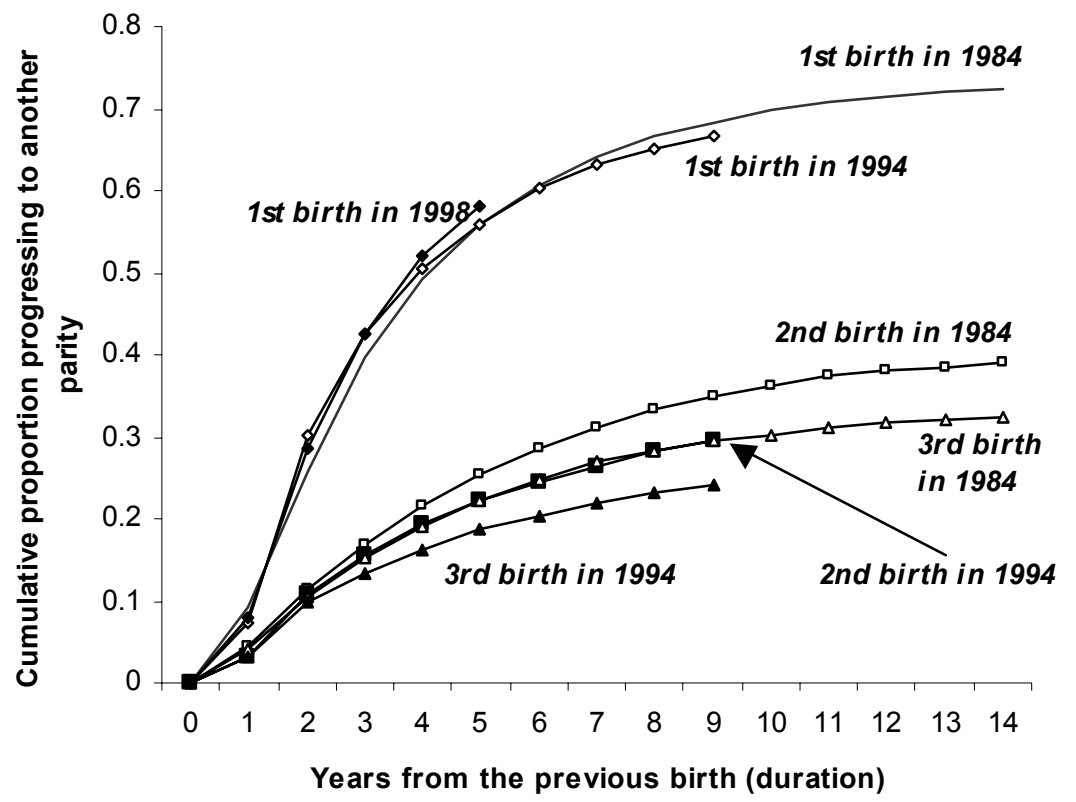

Sources: Author's computations based on the database of births in 1984-2004 provided by Statistics Austria. Note: Indicators are based on duration-parity fertility rates.

- Figure 13 indicates a considerable stability in the progression rates to second birth by duration since the first birth. Within ten years following the birth of the first child, more than two thirds of women give birth to the second one ( $70 \%$ among those having their first child in 1984 and $68 \%$ among those having their first child in 1994). 
- For women with two or three children, there has been a considerable decline in the frequency of additional childbearing. Ten years after the birth of the second child, only $30 \%$ of women who gave birth to a second child in 1994 gave birth to a third one at all, down from 35\% among women giving second birth in 1984. For those with three children, the proportions giving a fourth birth within ten years after the third one dropped from 29 to $24 \%$.

Figure 14:

Cumulative proportion of women giving birth to a second child by the year of birth of the first child (selected durations)

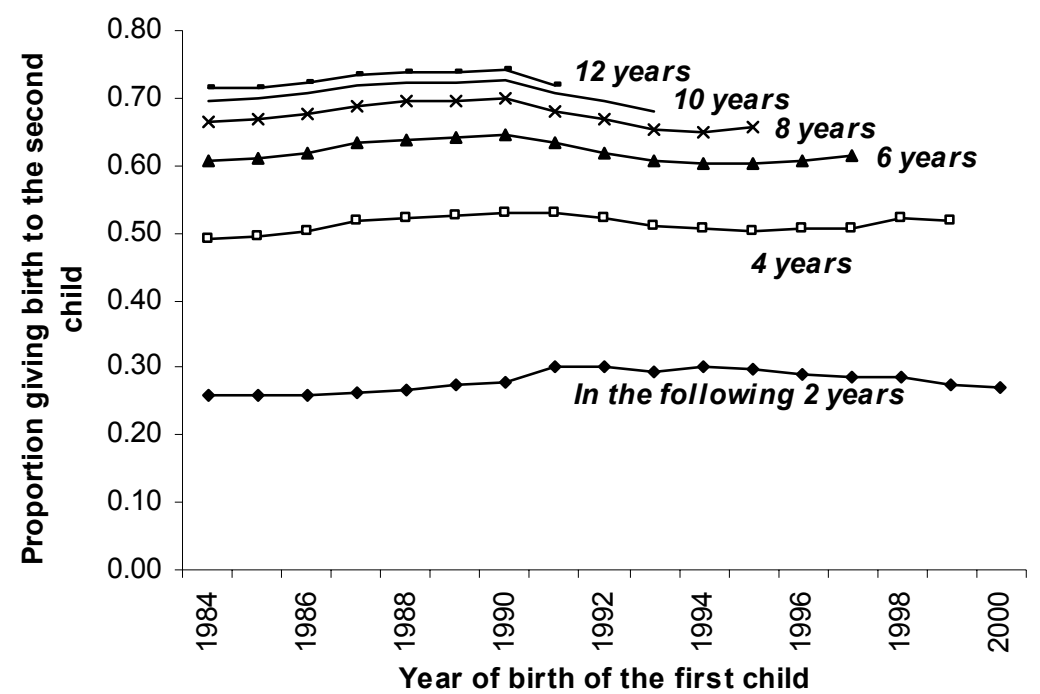

Sources: Author's computations based on the database of births in 1984-2004 provided by Statistics Austria. Note: Indicators are based on duration-parity fertility rates.

- The relative stability of second-birth patterns is further shown in Figure 14. About half the women with one child give birth to a second one within four years after the first birth and more than $70 \%$ within 10-12 years. The latter proportion has slightly declined for women giving first birth in the early 1990s, but this decline appears to be temporary. 


\section{Acknowledgement}

The author would like to thank Statistics Austria for providing the detailed database of births in 1984-2004. Thanks also to Richard Gisser for his comments and suggestions.

\section{References}

Council of Europe. 2005. Recent Demographic Developments in Europe 2004. Council of Europe. Strasbourg.

EUROSTAT. 2004 and 2005. NewCronos database. Theme 3: Population and social conditions. Accessed in October 2004 and June 2005. «http://epp.eurostat.cec.eu.int».

Sobotka, T. 2005. Childless societies? Trends and projections of childlessness in Europe and in the U.S. Paper presented at the 2005 PAA Conference, Philadelphia, 30 March2 April 2005.

Statistics Austria. 2005. Volkszählung 2001. Haushalte und Familien. Statistics Austria. Vienna.

Statistics Austria. 2005a. Demographisches Jahrbuch 2003. Statistics Austria. Vienna.

Statistics Austria. 1996. Volkszählung 1991. Haushalte und Familien. Herausgegeben vom Österreichischen Statistischen Zentralamt. Beiträge zur österreichische Statistik. Volume 1.030/26. Vienna.

Statistics Austria. 1989. Volkszählung 1981. Eheschließungs- und Geburtenstatistik. Herausgegeben vom Österreichischen Statistischen Zentralamt. Beiträge zur österreichische Statistik. Volume 630/27. Vienna

Statistics Austria. 1988. Demographisches Jahrbuch 1986. Herausgegeben vom Österreichischen Statistischen Zentralamt. Beiträge zur österreichische Statistik. Volume 873. Vienna.

United Nations. 1960. Demographic Yearbook 1959. United Nations, Department of International Economic and Social Affairs, New York. 